\title{
Is fruit dry matter concentration a useful predictor of ‘Honeycrisp’ apple fruit quality after storage?
}

\author{
T.L. Robinson ${ }^{1}$, A.D. Rufato 2 , L. Rufato ${ }^{3}$ and L.I. Dominguez ${ }^{1}$ \\ ${ }^{1}$ Dept. of Horticulture, NYSAES, Cornell University, Geneva, NY 14456, USA; ${ }^{2}$ EMBRAPA, Vacaria, Rio Grande du \\ Sul, Brazil; ${ }^{3}$ University of Santa Catarina, Lages Campus, Lages, Brazil.
}

\begin{abstract}
In climates such as New York State, USA, fruit quality (taste and bitter pit incidence) of 'Honeycrisp' apple varies significantly from year to year. Our research with 'Honeycrisp' indicates that when crop load is too high the tree cannot supply sufficient carbon, and other nutrients to give optimum fruit quality (taste, appearance and storageability). Similarly if weather patterns are cloudy, tree carbon acquisition is reduced and carbon supply for fruit growth is limited resulting in less than adequate resources for optimum fruit quality. In an attempt to predict 'Honeycrisp' eating quality and bitter pit incidence post storage we began a study in 2013 where we measured fruit quality characteristics at harvest of $\mathbf{3 0}$ orchards in western NY and 20 orchards in northern NY and correlated them with eating quality post storage after 4.5 months in air. The dry matter concentrations at harvest among orchards ranged from 11 to $18 \%$. Neither fruit dry matter no concentration or fruit mineral concentrations ( $\mathrm{N}, \mathrm{Ca}$ and $\mathrm{Ca} / \mathrm{N}$ and $\mathrm{K}+\mathrm{Mg} / \mathrm{Ca}$ ratio) were predictive of post-storage fruit quality. Fruit Ca concentration was also not predictive of post storage fruit bitter pit. Fruit samples were also treated with MCP or left untreated at harvest. MCP resulted in a small but significant improvement in fruit crunchiness, reduced disagreeable flavors and increased liking score of 'Honeycrisp' fruits.
\end{abstract}

Keywords: fruit mineral concentration, fruit Ca concentration, liking score, bitter pit, MCP

\section{INTRODUCTION}

Each season apple fruit growth is affected by the climate of that year, the crop load on the tree and the nutrient concentration of the fruit. In areas with variable summer climates such as New York State, this results in variable fruit quality from year to year. Various fruit quality characteristics measured at harvest or just before harvest may be useful to predict the quality of apple fruits post storage (assuming fruits are picked at optimum maturity).

Our previous research indicates that crop load is an important variable in determining 'Honeycrisp' apple fruit quality both at harvest and after storage (Robinson and Watkins, 2003; Robinson and Lopez, 2012). When crop load is too high the tree cannot supply sufficient carbon, and other nutrients to give optimum fruit quality (taste, appearance and storageability). Similarly if weather patterns are cloudy, tree carbon supply for fruit growth is limited resulting in less than adequate resources for optimum fruit growth and fruit quality. The amount of photosynthate loaded into the fruit as represented by fruit dry matter concentration (DMC) can be thought of as an integrator of crop load and weather. Palmer et al. $(2010,2013)$ has recently shown that apple fruit DMC is a good predictor of soluble solids concentration after storage and also consumer liking. Fruit DMC has been implemented in New Zealand as a tool to segregate high quality fruit from lower quality fruit (Mannering, 2012).

Another measure of the internal quality of an apple at harvest is fruit mineral concentration. Disorders such as bitter pit have been predicted from fruit mineral concentration such as calcium (Fallahi and Simons, 1996; Ferguson et al., 1979; Telias et al., 2006). Ratios of various elements in the fruit can be useful indicators of storageability, post storage fruit quality or susceptibility to disorders. Our previous work with Honeycrisp (Robinson and Lopez, 2009), showed crop load had a dominant effect on fruit quality, but 
fruit mineral nutrition also had a significant effect. High nitrogen increased fruit size but reduced fruit color, storage quality and crop value. In contrast potassium fertilization improved yield, fruit size, storage quality, and crop value while reducing the incidence of storage disorders and storage rots.

Our current research was an attempt to identify measurable fruit characteristics of 'Honeycrisp' apple at harvest that integrate the seasonal effects of crop load and climate, such as DMC or fruit mineral concentration that could be used to predict fruit quality after storage.

\section{MATERIALS AND METHODS}

In 2013, we sampled 10 mid-sized fruits from the exterior of each of 5 trees from 27 'Honeycrisp' apple orchards in Western New York State one week before harvest. Orchards were of variable age and on various rootstocks. Samples from each orchard were evaluated for dry matter concentration by measuring fresh and dry weight of 2 longitudinal wedges from each fruit. The combined wedges were bulked for fresh and dry weight measurements. Samples were oven dried for $48 \mathrm{~h}$ at $80^{\circ} \mathrm{C}$.

Fruit mineral concentration of macro and micronutrients was analyzed on a similar pair of wedges from each fruit but only the lower half off each wedge (calyx end) was used. Fruit nitrogen was determined by combustion and other macro and micro nutrients were determined Inductively Coupled Argon Plasma (ICAP) Samples were oven dried at $65^{\circ} \mathrm{C}$. before grinding and analysis at A\&L Great Lakes Laboratories, Inc. (Fort Wayne, Indiana 46808).

At harvest a sample of 5 fruits from each tree (75 apples orchard $\left.{ }^{-1}\right)$ from each of the 27 orchards was harvested at two harvest dates (September 27 and October 7). At each date sampled fruits were of optimum maturity based on fruit red color, background color and DA meter readings. Half of the fruits from each sample were treated with MCP for $24 \mathrm{~h}$ and the other half was left untreated. Fruits were stored for 5 days at $15^{\circ} \mathrm{C}$ as a pre-conditioning treatment and then stored until early February at $0^{\circ} \mathrm{C}$ in air. After storage the fruits were evaluated for external appearance and internal quality and taste by an untrained panel of 14 persons. Each person scored a sample of 5 fruits from each orchard and each harvest date with and without MCP for appearance, greasiness, and bitter pit. Each person also tasted a longitudinal wedge from each sample and scored it for "off" or disagreeable flavors, crunchiness and also gave it an overall "liking" score (Palmer et al., 2010).

Data were analyzed by regression (SAS) using combined data from all 27 orchards with both harvest dates and MCP treatment averaged for each orchard. We correlated fruit dry matter concentration or fruit mineral concentration at harvest with fruit taste and quality after storage with and without MCP.

\section{RESULTS}

\section{Fruit characteristics at harvest}

Fruit dry matter concentrations among orchards ranged from 10.8 to $16.5 \%$ but most of the orchards had dry matter concentrations in a narrow range between 13.6 and $15.2 \%$ (Figure 1). Fruit nitrogen concentration varied from $0.13-0.29 \%$, fruit calcium concentration varied from $0.025-0.06 \%$, fruit $\mathrm{N} / \mathrm{Ca}$ ratio varied from $2-8$ and fruit $\mathrm{K}+\mathrm{Mg} / \mathrm{Ca}$ ratio varied from 16-45 (Figure 1). Fruits were harvested in two picks. First on September 27 when fruit firmness was $6.4 \mathrm{~kg}$, soluble solids were $11.7 \%$ and DA meter readings ranged from 0.84 1.29. The second pick was on October 7 when fruit firmness was $5.6 \mathrm{~kg}$, soluble solids were $11.1 \%$ and DA meter readings ranged from 0.34-0.64.

\section{Post storage fruit quality}

After the 4.5-month storage period, fruit firmness was $5.6 \mathrm{~kg}$ and soluble solids were $11.5 \%$ for fruit from the first harvest and $5.4 \mathrm{~kg}$ firmness and $11.2 \%$ soluble solids for fruit from the second harvest. 


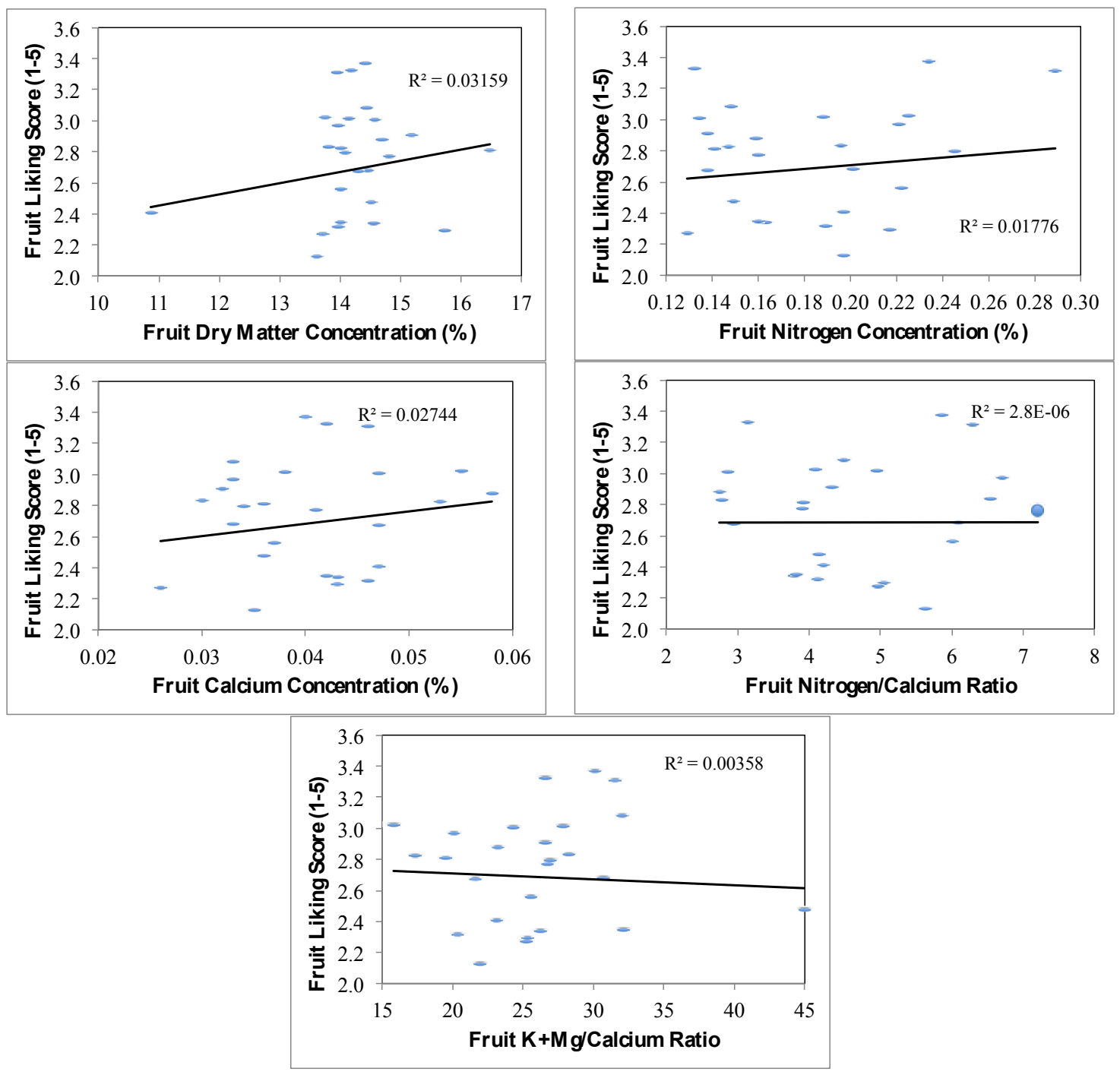

Figure 1. Relationship of fruit dry matter concentration, fruit nitrogen concentration, fruit calcium concentration, fruit nitrogen/calcium ratio, and fruit $\mathrm{K}+\mathrm{Mg} / \mathrm{Ca}$ ratio of 'Honeycrisp' fruits at harvest and fruit liking score after a 4.5 month storage.

\section{Correlation of fruit characteristics at harvest and post storage fruit quality}

After the 4.5-month storage period, fruit liking score varied considerably between orchards but was not related to fruit dry matter concentration or any fruit mineral concentration (Figure 1). No other measure of fruit quality after storage (crunchiness, level of disagreeable flavors, soluble solids, or storage disorders) was related to fruit dry matter concentration or any fruit mineral concentration (data not shown).

Fruit bitter pit incidence after storage was relatively low but the range was substantial (range from $0-30 \%$ ) for the 27 orchards (Figure 2). Bitter pit incidence was not related to fruit calcium concentration although there was a slight negative trend with higher fruit calcium level.

Fruits treated with MCP at harvest were slightly less firm but had slightly greater fruit soluble solids concentration, crunchiness, reduced disagreeable flavors reduced bitter pit incidence and increased liking score (Table 1). 


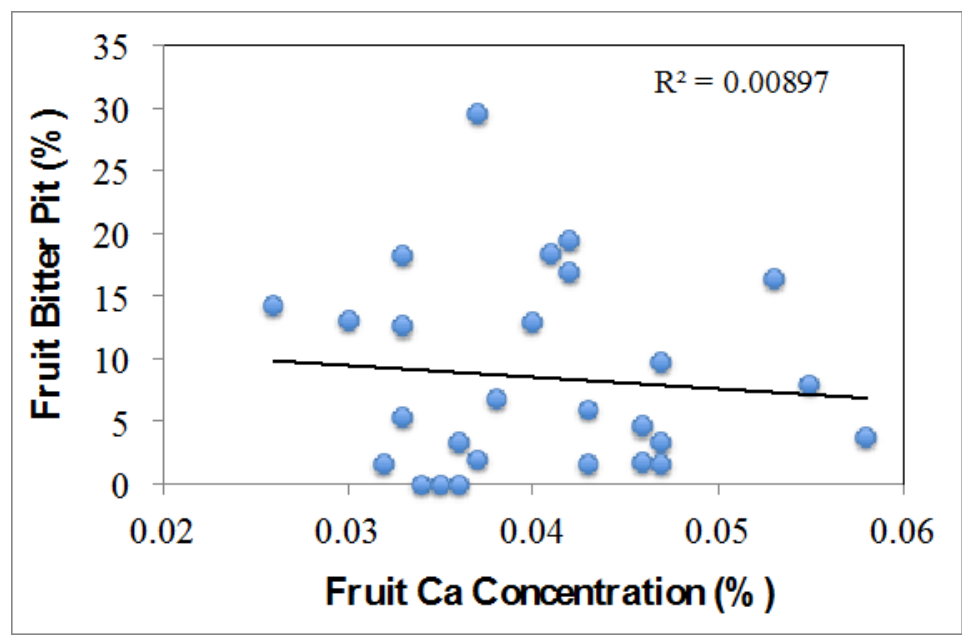

Figure 2. Relationship of fruit Ca concentration of 'Honeycrisp' fruits at harvest and fruit bitter pit after a 4.5-month storage.

Table 1. Effect of MCP on 'Honeycrisp' fruit quality after 4.5 months of air storage.

\begin{tabular}{lcccccc}
\hline Treatment & $\begin{array}{c}\text { Fruit } \\
\text { firmness } \\
(\mathbf{k g})\end{array}$ & $\begin{array}{c}\text { Fruit } \\
\text { soluble } \\
\text { solids } \\
(\%)\end{array}$ & $\begin{array}{c}\text { Fruit } \\
\text { crunchiness } \\
\text { (1-5 scale) }\end{array}$ & $\begin{array}{c}\text { Disagreeable } \\
\text { flavors } \\
\text { (1-3 scale) }\end{array}$ & $\begin{array}{c}\text { Fruit } \\
\text { bitter pit } \\
(\%)\end{array}$ & $\begin{array}{c}\text { Overall } \\
\text { fruit liking } \\
\text { (1-5 scale) }\end{array}$ \\
\hline No MCP & $5.6 \mathrm{a}^{1}$ & $11.2 \mathrm{~b}$ & $3.0 \mathrm{~b}$ & $1.6 \mathrm{a}$ & $9.1 \mathrm{a}$ & $2.5 \mathrm{~b}$ \\
MCP & $5.4 \mathrm{~b}$ & $11.5 \mathrm{a}$ & $3.1 \mathrm{a}$ & $1.5 \mathrm{~b}$ & $6.2 \mathrm{~b}$ & $2.7 \mathrm{a}$ \\
\hline
\end{tabular}

${ }^{1}$ Means followed by the same letter are not significantly different at $P<0.05$ LSD.

\section{DISCUSSION}

This research failed to identify any fruit characteristic of 'Honeycrisp' apple at harvest that was strongly predictive of fruit quality or taste after storage. The lack of relationship of fruit dry matter concentration at harvest and consumer liking of the fruit after storage is in contrast to results of Palmer et al. $(2010,2013)$ who showed that apple fruit dry matter concentration was predictive of soluble solids concentration after storage and consumer liking. In their research fruit DMC was a more reliable predictor of total soluble solids after 12 weeks of air storage at $0.5^{\circ} \mathrm{C}$ than TSS at harvest for both 'Royal Gala' and 'Scifresh'. Fruit DMC was also positively related to flesh firmness, although this relationship was not as strong as that seen with soluble solids and was more dependent on cultivar. Consumer studies showed that consumer preference was positively related to fruit DMC of 'Royal Gala' apples. Their research suggests that for individual fruit within any cultivar, low fruit DMC will not give a good eating experience.

The lack of relationship of DMC and post storage quality in our study indicates that the relationship is not as robust as previous studies indicate. At least with 'Honeycrisp' it appears not to be predictive. 'Honeycrisp' is a unique apple compared to most other cultivars. It has low ethylene production and shows a unique starch pattern degradation pattern and has numerous storage disorders. Thus the lack of relationship of fruit dry matter concentration at harvest and consumer liking of the fruit after storage could be a unique characteristic of 'Honeycrisp' apple or it could be related to the narrow range of DMC for most of the orchards in our study.

Our present study also showed no relationship between fruit mineral concentration and fruit quality after storage. We also saw no relationship between fruit calcium concentration and bitter pit incidence. This supports our previous work with 'Honeycrisp' where we found no relationship between fruit Ca concentration and fruit bitter pit, fruit 
firmness, incidence of disorders or storage rots (Robinson and Lopez, 2009, 2012). This is in contrast with other work on 'Honeycrisp and other cultivars (Fallahi and Simons, 1996; Ferguson et al., 1979; Telias et al., 2006). In our earlier work, we also could not show a benefit of fruit Ca sprays on fruit Ca levels or bitter pit incidence. Other foliar nutrient sprays $(\mathrm{N}, \mathrm{Mg}, \mathrm{Zn}, \mathrm{B}) \mathrm{had}$ little effect on yield, fruit quality, crop value, storage disorders or storage rots. However we did find a consistent relationship between fruit $\mathrm{P}$ concentration and incidence of disorders (primarily bitter pit). We also found a consistent relationship between fruit P:S ratio and fruit red color.

The uniqueness of 'Honeycrisp' might also explain the lack of correlations between fruit mineral concentrations or ratios of nutrients and post storage fruit quality. This might require unique mineral nutrient standards for 'Honeycrisp'.

The expected effect of MCP of increased fruit firmness after storage also seemed to be reduced with 'Honeycrisp'. This cultivar does not show high firmness levels at harvest and loses firmness slowly in storage but exhibits a high level of crunchiness. Although MCP did not improve firmness it did improve crunchiness and liking score while reducing disagreeable flavors and bitter pit incidence.

\section{CONCLUSIONS}

Finding a predictive tool of 'Honeycrisp' storage quality was the goal of this project. Neither fruit dry matter concentration or fruit mineral concentrations or ratios of fruit nutrients were good predictors of 'Honeycrisp' fruit quality after storage. MCP resulted in a small but significant improvement in fruit crunchiness, reduced disagreeable flavors and increased liking score of 'Honeycrisp' fruits.

\section{Literature cited}

Fallahi, E., and Simons, B.R. (1996). Interrelations among leaf and fruit mineral nutrients and fruit quality in 'Delicious' apples. J. Tree Fruit Prod. 1 (1), 15-25 https://doi.org/10.1300/J072v01n01_02.

Ferguson, I.B., Reid, M.S., and Prasad, M. (1979). Calcium analysis and the prediction of bitter pit in apple fruit. N. Z. J. Agric. Res. 22 (3), 485-490 https://doi.org/10.1080/00288233.1979.10430778.

Mannering, R. (2012). Higher the DM the better the taste. The Orchardist 86 (10), 18-19.

Palmer, J.W., Harker, F.R., Tustin, D.S., and Johnston, J. (2010). Fruit dry matter concentration: a new quality metric for apples. J. Sci. Food Agric. 90 (15), 2586-2594 https://doi.org/10.1002/jsfa.4125. PubMed

Palmer, J., Diack, R., Johnston, J., and Boldingh, H. (2013). Manipulation of fruit dry matter accumulation and fruit size in 'Scifresh' apple through alteration of the carbon supply, and its relationship with apoplastic sugar composition. J. Hortic. Sci. Biotechnol. 88 (4), 483-489 https://doi.org/10.1080/14620316.2013.11512995.

Robinson, T., and Lopez, S. (2009). Crop load and nutrition affect 'Honeycrisp' apple quality. NY Fruit Quarterly 17 (2), 25-28.

Robinson, T., and Lopez, S. (2012). Crop load affects 'Honeycrisp' fruit quality more than nitrogen, potassium, or irrigation. Acta Hortic. 940, 529-537 https://doi.org/10.17660/ActaHortic.2012.940.76.

Robinson, T.L., and Watkins, C.B. (2003). Crop load of Honeycrisp affects not only fruit size but also many quality attributes. New York Fruit Quarterly 11 (3), 7-10.

Telias, A., Hoover, E., Rosen, C., Bedford, D., and Cook, D. (2006). The effect of calcium sprays and fruit thinning on bitter pit incidence and calcium content in 'Honeycrisp' apple. J. Plant Nutr. 29 (11), 1941-1957 https://doi.org/ 10.1080/01904160600927492. 
